\title{
Review
}

\section{Renal glucose production and utilization: new aspects in humans}

\author{
M .StumvolI ${ }^{1}$, C. M eyer ${ }^{2}$, A . M itrakou ${ }^{3}$, V. N adkarni ${ }^{2}$, J . E . G erich ${ }^{2}$ \\ ${ }^{1}$ Medizinische Universitätsklinik, Tübingen, Germany \\ ${ }^{2}$ University of Rochester School of Medicine, Rochester, New York, USA \\ ${ }^{3}$ Athens University, Athens, Greece
}

Summary According to current textbook wisdom the liver is the exclusive site of glucose production in humans in the postabsorptive state. Although many animal and in vitro data have documented that the kidney is capable of gluconeogenesis, production of glucose by the human kidney in the postabsorptive state has generally been regarded as negligible. This traditional view is based on net balance measurements which, other than after a prolonged fast or during metabolic acidosis, showed no significant net renal glucose release. However, recent studies have refuted this view by combining isotopic and balance techniques, which have demonstrated that renal glucose production accounts for $25 \%$ of systemic glucose production. Moreover, these studies indicate that glucose production by the human kidney is stimulated by epinephrine, inhibited by insulin and is excessive in diabetes mellitus. Since renal glucose release is largely, if not exclusively, due to gluconeogenesis, it is likely that the kidney is as important a gluconeogenic organ as the liver. The most important renal gluconeogenic precursors appear to be lactate, glutamine and glycerol. The implications of these recent findings on the understanding of the physiology and pathophysiology of human glucose metabolism are discussed. [Diabetologia (1997) 40: 749-757].

Keywords Endogenous glucose production, gluconeogenesis, glycogenolysis, liver, diabetes mellitus.
In the postabsorptive state, glucose must be continuously delivered into the circulation in order to meet energy requirements of tissues such as brain cells and erythrocytes, which use only glucose as their fuel. Only liver and kidney are able to release glucose into the circulation because other tissues lack glucose 6-phosphatase [1]. Release of glucose into the circulation occurs via two processes: gluconeogenesis, the de novo synthesis of glucose from non-glucose precursors; and glycogenolysis, the breakdown of glycogen, a carbohydrate polymer formed directly from glucose or indirectly via gluconeogenesis [2]. Current evi-

Corresponding author: Dr. M.Stumvoll, Medizinische Universitätsklinik, Otfried-Müller-Str.10, D-72076 Tübingen, Germany

A bbreviations: IDDM, Insulin-dependent diabetes mellitus; NIDDM, non-insulin dependent diabetes mellitus. dence indicates that in postabsorptive normal humans (overnight fasted state) gluconeogenesis and glycogenolysis each contribute approximately $50 \%$ of the glucose delivered into the systemic circulation [3].

It has long been recognized that on a gram-forgram tissue basis, the gluconeogenic capacity of the kidney exceeds that of the liver [4]. Nevertheless, based on net balance experiments finding no significant difference in arterial and renal vein glucose concentrations in the basal state [5-7], until recently the human kidney has generally been regarded as contributing insignificantly to postabsorptive glucose production [8-10]. However, recent studies of renal glucose metabolism employing isotope techniques in vivo which permit individual assessment of glucose production and utilization, have clearly demonstrated that the kidney makes an appreciable contribution to both systemic glucose production and glucose utilization [11-13]. 
Table 1. Glucose and fuels - human renal net balance studies

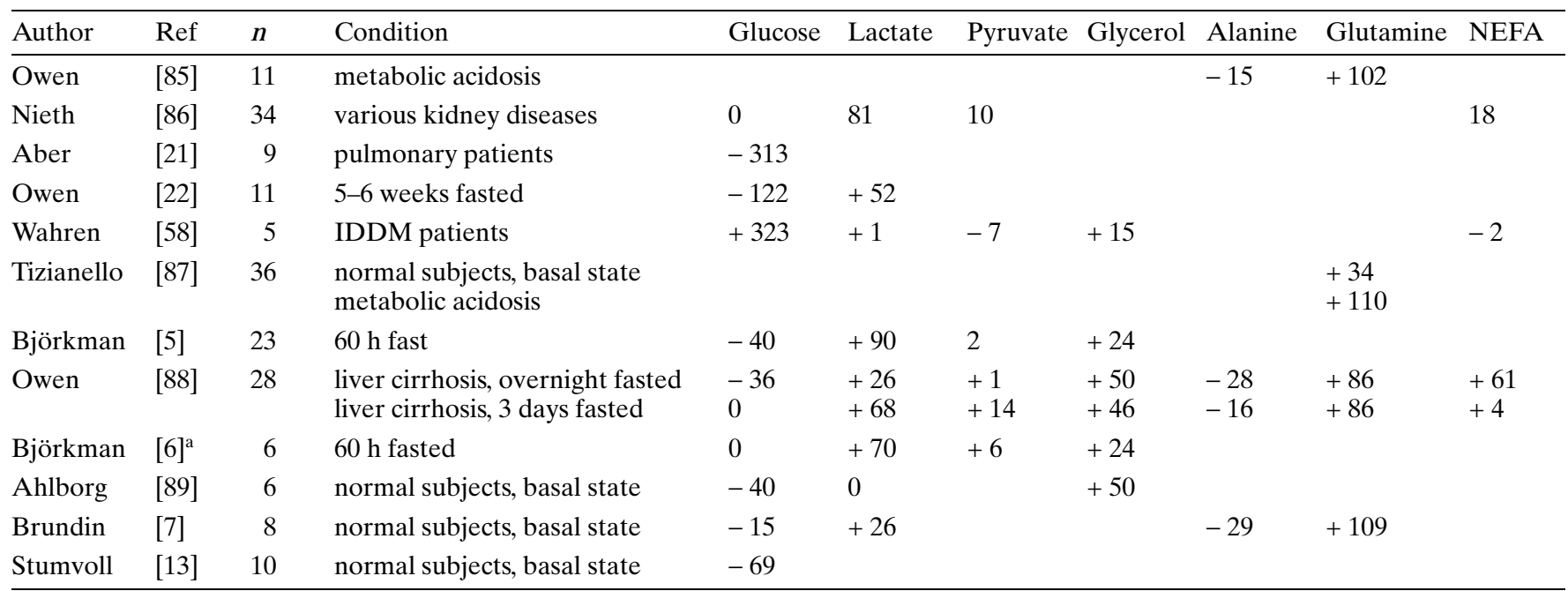

a Assumed renal blood flow 1.4 1/min

NEFA, Non-esterified fatty acids

\section{Historical aspects}

In vitro and animal studies. The ability of mammalian kidney to synthesize glucose from non-carbohydrate precursors was demonstrated in vitro 60 years ago by Benoy and Elliot [14], who observed that addition of lactate and pyruvate to kidney cortex slices increased the glucose concentration of the medium. In 1938, Bergman and Drury [15] observed that rabbits, which had been both hepatectomized and nephrectomized, required more exogenous glucose to maintain the normal blood glucose level than animals which had undergone hepatectomy alone. Interestingly, the authors did not conclude that the kidney makes glucose but rather that the kidney normally excretes a substance that if retained in the body causes a marked increase in the glucose requirement. In the $1940 \mathrm{~s}$, net renal glucose release was found to increase in rats during hypoglycaemia after hepatectomy [16] and a greater rate of fall of blood glucose in dogs that had undergone nephrectomy with hepatectomy compared to hepatectomy only [17]. In the early $1950 \mathrm{~s}$ numerous in vitro studies further substantiated the gluconeogenic capacity of renal cortical tissue [1820].

H uman studies. The first evidence for glucose production by the human kidney originates from the year 1966, when Aber et al. [21] showed substantial net renal glucose release of as much as $880 \mu \mathrm{mol} / \mathrm{min}$ in patients with severe chronic respiratory acidosis and also a lesser amount in non-acidotic subjects. This study nevertheless has generally been interpreted to indicate that net renal glucose release only occurred in subjects with acidosis. Three years later, Owen et al. [22] documented that net renal glucose output, though negligible in the postabsorptive state, contributed nearly $50 \%$ to systemic glucose appearance after 4-6 weeks of fasting. Studies during the following three decades, did not find net renal glucose release in excess of $10 \%$ of systemic glucose appearance under physiological conditions (Table 1). These observations led to the traditional perception of the human kidney as playing a minor role in carbohydrate metabolism $[9,23]$.

\section{Methodological considerations}

The study of renal substrate metabolism in general is complicated by the high rate of renal blood flow, usually reported in the range of 1200 and $1800 \mathrm{ml} / \mathrm{min}$. This results in a very small arteriovenous difference for substrate concentrations, and presents an analytical challenge. The same applies to splanchnic balance studies, where blood flow is equally high and arteriovenous differences similarly small. Use of high-performance liquid chromatography (HPLC), which permits precise determination of arteriovenous differences in plasma concentrations and specific activities $[24,25]$ has helped to minimize this problem.

The conclusions drawn in previous studies (Table 1) which led to the traditional view that the human kidney releases insignificant amounts of glucose, were based on net balance data of glucose, i. e. the mathematical product of arterio-renal venous difference of glucose concentrations $(\mu \mathrm{mol} / \mathrm{ml}$, obtained through a sampling catheter in a renal vein) and renal blood flow ( $\mathrm{ml} / \mathrm{min})$. The net balance approach, however, does not take into consideration simultaneous release and uptake of glucose by the kidney. Uptake and release are distinct processes subject to separate regulation and occurring in different locations within the kidney. Glucose utilization occurs predominantly 


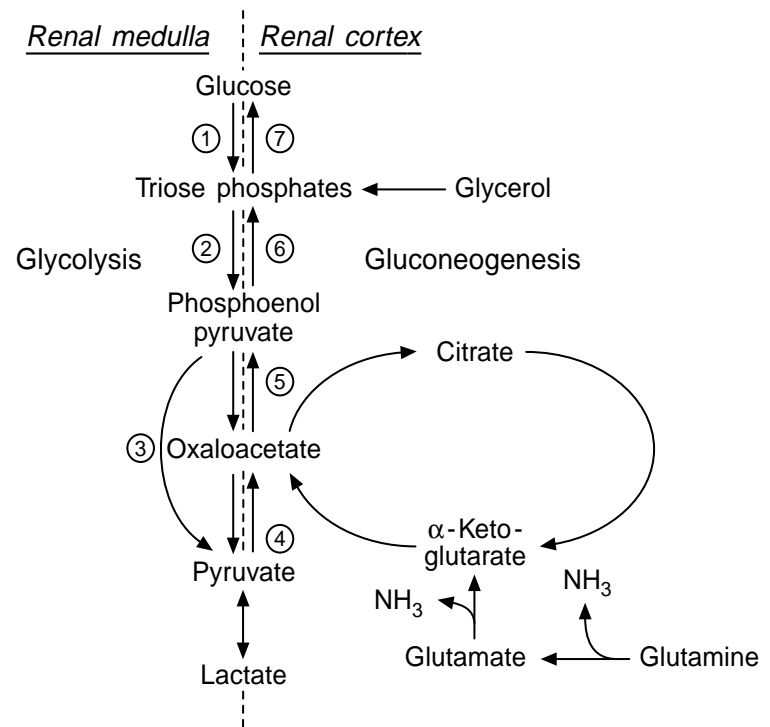

Fig. 1. Renal glycolysis and gluconeogenesis - pathway and enzyme localization. The glycolytic key enzymes (1) hexokinase, (2) phosphofructokinase and (3) pyruvate kinase are predominantly localized in cells of the renal medulla. The key enzymes of gluconeogenesis (4) pyruvate carboxylase, (5) phosphoenol pyruvate carboxykinase, (6) fructose-1,6-biphosphatase and (7) glucose 6-phosphatase are found mainly in renal cortical cells

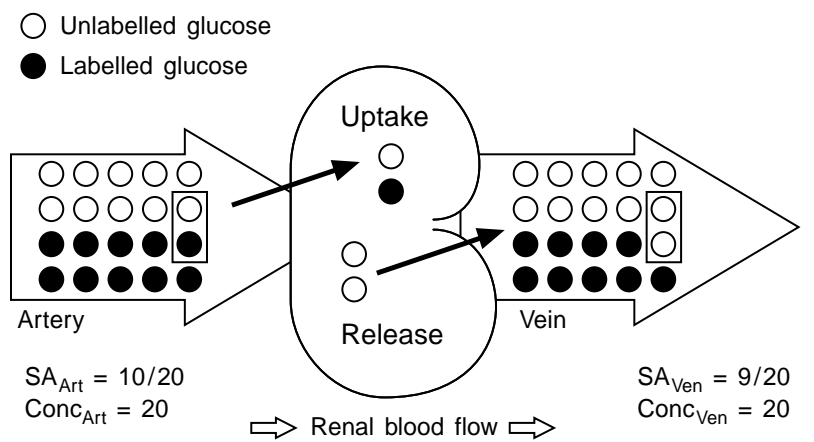

Fig. 2. Principle of isotopic determination of fractional extraction of glucose across the kidney. Assuming 20 parts glucose per unit volume, 10 of which are labelled isotopically, entering the kidney (artery) and a renal blood flow of 1 unit volume per min, 20 parts glucose per unit volume leaving the kidney (vein) results in a net balance of 0 . Uptake of two parts of glucose does not distinguish between labelled and unlabelled, while only unlabelled glucose can be released by the kidney. Thus the arterial specific activity of $10 / 20$ is diluted to $9 / 20$ in the vein. Fractional extraction equals (10/20-9/20)/(10/ $20)=0.1$. Glucose uptake is calculated as fractional extraction times renal blood flow times arterial concentration $\left(\mathrm{Conc}_{\mathrm{Art}}\right)$ or $0.1 \times 1 / \mathrm{min} \times 20 \mathrm{parts}=2 \mathrm{parts} / \mathrm{min}$. Since net balance equals 0 , release equals uptake equals 2 parts $/ \mathrm{min}$

in the renal medulla, whereas glucose production is confined to the cortex [23, 26-28] (Fig. 1).

Thus, by merely representing the difference between uptake and release of a substrate, net balance measurements cannot evaluate the contribution of an organ to the entry and removal of a substrate from the systemic circulation. Moreover, inferences based on net balance measurements may lead to an underestimation of the role of an organ in the overall metabolism of a substrate. For example, with isotope dilution determination of systemic glucose flux, entry of glucose into the circulation is quantified by the dilution of the plasma glucose tracer concentration by unlabelled glucose released into the circulation [29]. If the kidney were to take up and release glucose at equal rates, there would be no arterio-renal venous glucose difference, and net glucose balance would be zero. Nevertheless, release of unlabelled glucose into the circulation by the kidney would dilute the plasma glucose tracer concentration and contribute to the isotopic estimation of glucose entry into the circulation (Fig. 2). Similar considerations are true for the contribution of the kidney to removal of glucose from the circulation as determined isotopically. Therefore, a combination of net balance and isotopic techniques with measurement of substrate as well as tracer concentrations is necessary to assess individually the uptake and release of a substrate by an organ [29-31].

\section{Uptake and release of glucose by the kidney}

As indicated above, because the kidney uses and produces glucose, only a combination of isotopic and net balance techniques can provide a reliable assessment of renal glucose release. In 1978, Kida et al. [32] found a renal contribution of $25 \%$ to systemic glucose production in rats by injecting a bolus of $\left[{ }^{14} \mathrm{C}\right]$ glucose and comparing the decline of blood glucose concentration and $\left[{ }^{14} \mathrm{C}\right]$ glucose concentration following hepatectomy. In intact animals the isotopic net balance approach was not employed until recently, when a significant renal uptake of glucose was shown in dogs accounting for as much as $30 \%$ of glucose removal from the circulation under postabsorptive conditions $[11,12]$. Since renal net balance was within the expected range, i.e. close to zero, the data also indicated that the kidney was responsible for over $20 \%$ of glucose entry into plasma in postabsorptive dogs (Table 2).

An analogous approach was recently used in healthy, postabsorptive humans [13]. These studies showed, as expected, that the human kidney simultaneously takes up and releases appreciable amounts of glucose. Renal glucose release accounted for about $25 \%$ of all glucose released into the circulation and its uptake of glucose accounted for approximately $20 \%$ of all glucose removed from the circulation [13] (Table 2). These results thus refuted textbook wisdom that the human kidney plays a minor role in glucose homeostasis.

Regarding the mechanism for renal glucose release, the normal human kidney does not contain 
Table 2. Uptake and release of glucose by the kidney-studies measuring fractional extraction of glucose across the kidney

\begin{tabular}{|c|c|c|c|}
\hline & $\begin{array}{l}\text { Cersosimo } \\
\text { et al. } \\
{[12]} \\
\text { dogs }\end{array}$ & $\begin{array}{l}\text { McGuiness } \\
\text { et al. } \\
\text { [11] } \\
\text { dogs }\end{array}$ & $\begin{array}{l}\text { Stumvoll } \\
\text { et al. } \\
\text { [13] } \\
\text { humans }\end{array}$ \\
\hline $\begin{array}{l}\text { Glucose turnover } \\
\left(\mu \mathrm{mol} \times \mathrm{kg}^{-1} \times \mathrm{min}^{-1}\right)\end{array}$ & 18.5 & 15.0 & 11.4 \\
\hline $\begin{array}{l}\text { Renal glucose net balance } \\
\left(\mu \mathrm{mol} \times \mathrm{kg}^{-1} \times \mathrm{min}^{-1}\right)\end{array}$ & 1.4 & 1.4 & -0.9 \\
\hline $\begin{array}{l}\text { Renal glucose uptake } \\
\left(\mu \mathrm{mol} \times \mathrm{kg}^{-1} \times \mathrm{min}^{-1}\right) \\
(\% \text { of turnover })\end{array}$ & $\begin{array}{l}5.8 \\
31\end{array}$ & $\begin{array}{l}3.3 \\
22\end{array}$ & $\begin{array}{l}2.3 \\
20\end{array}$ \\
\hline $\begin{array}{l}\text { Renal glucose release } \\
\left(\mu \mathrm{mol} \times \mathrm{kg}^{-1} \times \mathrm{min}^{-1}\right) \\
(\% \text { of turnover })\end{array}$ & 24 & 13 & $\begin{array}{l}3.2 \\
28\end{array}$ \\
\hline
\end{tabular}

Table 3. Factors affecting renal gluconeogenesis

\begin{tabular}{lll}
\hline & Stimulation & Inhibition \\
\hline Hormones & $\begin{array}{l}\text { Catecholamines } \\
\text { Glucocorticoides } \\
\text { Aldosterone }\end{array}$ & Adrenalectomy \\
& $\begin{array}{l}\text { Insulin deficiency } \\
\text { (diabetes mellitus) }\end{array}$ & Insulin \\
& $\begin{array}{l}\text { Parathyroid hormone } \\
\text { Vitamin D }\end{array}$ & Calcitonin \\
& $\begin{array}{l}\text { Thyroxine } \\
\text { Growth hormone } \\
\text { Angiotensin }\end{array}$ & \\
A cid base balance & $\begin{array}{l}\text { Acidosis } \\
\text { Pthers }\end{array}$ & Alkalosis \\
& $\begin{array}{l}\text { Exercise } \\
\text { High protein diet }\end{array}$ & \\
& Liver failure & Branched-chain \\
Non-esterified & amino acids \\
fatty acids & \\
\hline
\end{tabular}

In vitro and animal data summarized from $[26,27]$

appreciable glycogen stores [33]. Moreover, renal cells which have appreciable glucose phosphorylating capacity and thus the ability to accumulate glycogen have relatively little glucose 6-phosphatase activity, whereas cells having little phosphorylating capacity possess abundant activity of glucose 6-phosphatase and other gluconeogenic enzymes [28, 34]. It is thus likely that release of glucose by the normal kidney is due mainly if not exclusively to gluconeogenesis. Consistent with this conclusion is the fact that the reported net renal uptake of key gluconeogenic precursors (e.g. lactate, glycerol, glutamine and other amino acids) is sufficient to account for all of the observed release of glucose by the kidney [5-7].

\section{Hormonal regulation of renal glucose production}

In vitro studies in isolated, perfused animal kidneys and cortex slices indicate that hepatic and renal glucose release differ with respect to nutritional, acid-base-balance and hormonal influences as reviewed elsewhere [26] (Table 3). Since this review deals with in vivo studies in humans, we will highlight recent observations of hormonal effects on glucose production by the human kidney.

Insulin. Many studies have shown that insulin inhibits gluconeogenesis in vitro in kidney cortex slices [35] and in vivo in diabetic animals treated with insulin [32]. The observation in humans that during euglycaemic-hyperinsulinaemic clamp experiments systemic glucose appearance, the sum of hepatic plus renal, decreases virtually to zero [36] strongly suggests that insulin suppresses renal glucose production in humans. In normal dogs intra-renal infusion of insulin, designed not to suppress systemic glucose appearance, decreased renal glucose production of the infused kidney by about $75 \%$ [12]. Whether an analogous mechanism is operative in normal humans has not been directly assessed. Nevertheless, in a study using a combination of net balance and isotopes, repletion of insulin suppressed increased renal glucose production in insulin-dependent diabetic (IDDM) patients by $50 \%$, while decreasing hepatic glucose production by $80 \%$ [37]. This suggests that in diabetes, at least, the kidney is less sensitive to the suppressive effect of insulin on glucose production than is the liver.

G lucagon. In vitro studies suggest that glucagon does not stimulate renal gluconeogenesis [38]. Infusion of glucagon designed to increase plasma glucagon concentrations threefold in normal volunteers had no effect on renal glucose production measured isotopically while doubling hepatic glucose production [39]. This is consistent with a previous report where suppression of glucagon secretion by infusion of somatostatin in fasted humans inhibited net splanchnic but not net renal glucose release [5].

E pinephrine. Catecholamines have been shown to stimulate gluconeogenesis in isolated renal cortical tissue [40]. Moreover, infusion of epinephrine has been shown to accelerate systemic glucose production in humans [41]. In a recent study in healthy humans, designed to measure renal glucose production isotopically, epinephrine acutely increased systemic glucose production by $60 \%$, hepatic glucose release by $50 \%$ and renal glucose production by $100 \%$ [13]. It is of note that in this study, infusion of epinephrine, which resulted in circulating concentrations of epinephrine similar to those observed during hypoglycaemia [42], caused a sustained increase in renal glucose release that after $3 \mathrm{~h}$ accounted for essentially all of the increased appearance of glucose in the circulation (Fig. 3). The stimulatory effect of epinephrine on renal glucose production could be direct via 


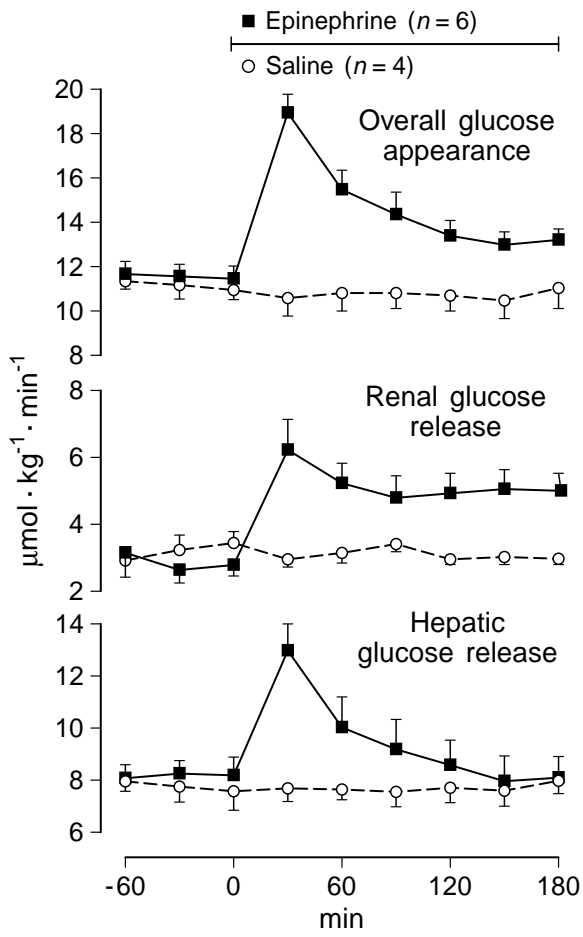

Fig. 3. Overall glucose appearance, renal and hepatic glucose release in the basal state and during infusion of saline or epinephrine (reproduced from J Clin Invest with permission [13])

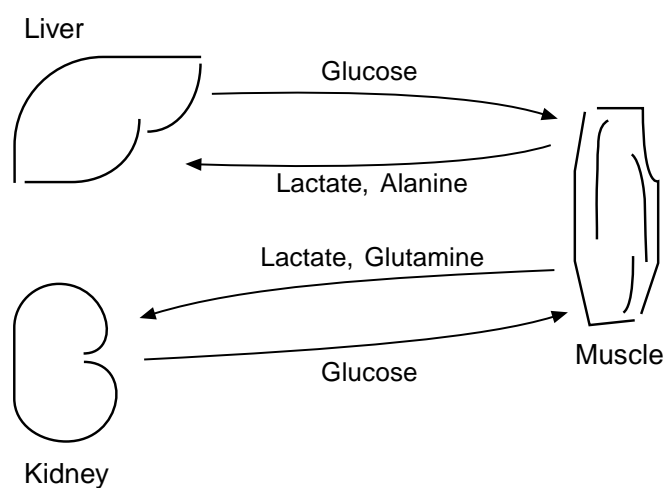

Fig. 4. Glucose-lactate-(Cori)cycle, glucose-alanine-cycle, and glucose-glutamine-cycle

cAMP-mediated stimulation of renal key gluconeogenic enzymes, as shown in vitro [40], or indirect through increased substrate availability since epinephrine has been shown to increase the availability of gluconeogenic precursors [41].

O ther hormones. There are animal studies showing the effects of growth hormone, thyroxine, glucocorticoids and other hormones on renal glucose metabolism (Table 3), but to date no human data are available.
Renal gluconeogenic substrates

In humans, lactate, glutamine, alanine and glycerol are the main gluconeogenic precursors [2]. Based on splanchnic net balance measurements, however, uptake of these precursors by the liver can only account for $50 \%$ of total gluconeogenesis [43] assuming gluconeogenesis to be $50 \%$ of overall glucose production (i.e. gluconeogenesis plus glycogenolysis). In vitro studies have suggested lactate, pyruvate, glycerol, fructose, proprionate and certain amino acids including glutamine, glutamate and proline as potential renal precursor candidates [27]. Studies of uptake of potential gluconeogenic precursors by the human kidney have shown net uptake of glutamine and glycerol, but essentially no arteriovenous difference for alanine [5-7]. Moreover, infusion of glycerol has been reported to increase renal glucose output whereas infusion of alanine has not [6]. Human net balance data for lactate are somewhat controversial, ranging from virtually zero [7] to significant net uptake after a 60-h fast [5] (Table 1). However, to quantitatively evaluate the potential role of renal gluconeogenic precursors, one must measure their conversion to glucose by the kidney [29]. Conversion of ${ }^{14} \mathrm{C}$-labelled glycerol to glucose by the canine kidney has been demonstrated to contribute $10 \%$ to renal gluconeogenesis [12].

In vitro studies indicate that glutamine is one of the main gluconeogenic precursors used by the kidney [44-47]. Recent observations suggest that in humans fasted overnight, approximately equal amounts of glucose are made gluconeogenetically from glutamine and alanine [48]. However, the human liver, has been reported to take up very little or no glutamine [49-51] whereas glutamine accounts for approximately $60 \%$ of all amino acids taken up by human kidneys [7]. Using [U- ${ }^{14} \mathrm{C}$ ]glutamine and determining the rate of conversion of glutamine to glucose directly via a renal vein catheter, it has been shown that in humans fasted overnight almost $80 \%$ of systemic glutamine gluconeogenesis takes place in the kidney and that $15-20 \%$ of renal glucose production is accounted for by renal glutamine gluconeogenesis [39]. Alanine on the other hand, was not converted to glucose by the kidney and thus alanine gluconeogenesis occurred exclusively in the liver [52]. This indicates gluconeogenic substrate selectivity of kidney and liver for glutamine and alanine, respectively, in humans (Fig. 4). No tracer data for other substrates in humans are available.

\section{Diabetes mellitus}

It has long been known that renal glucose metabolism is altered in animals rendered diabetic experimentally $[53,54]$. In alloxan-diabetic rats renal gluconeogenesis 
was increased twofold compared to normal rats [32]. Several issues regarding the underlying mechanism, however, have remained controversial. To what extent the accelerated renal gluconeogenesis is due to acidosis accompanying insulin-deficient diabetes [55], to altered substrate availability [56] or to stimulation of gluconeogenic enzymes [55, 57]. Since diabetic kidneys contain measurable amounts of glycogen [33], conceivably, not all of the release of glucose might be due to gluconeogenesis.

To date there have been only two studies in IDDM patients evaluating renal glucose metabolism [37, 58]. In both there was substantial net uptake of glucose. The one isotopic study permitting independent determination of production and utilization of glucose, showed that although there was net renal glucose uptake renal glucose production in IDDM patients was increased proportionately to systemic glucose appearance [37]. To date no data in non-insulin-dependent (NIDDM) patients are available. However, indirect evidence for accelerated renal glucose production in this condition comes from the recent observation that systemic glutamine gluconeogenesis is increased in NIDDM patients [59]. If most of the glutamine conversion to glucose occurs in the kidney, as it does in normal subjects [39], these data would indicate that renal glutamine gluconeogenesis is increased in NIDDM.

Implications for the understanding of human carbohydrate metabolism

The results obtained so far in humans have several implications for the understanding of human carbohydrate metabolism. The observations that in humans renal glucose production contributes approximately $25 \%$ to systemic glucose production and renal glucose uptake accounts for $20 \%$ of systemic glucose removal indicate an important role of the human kidney for glucose homeostasis. Essentially all renal glucose production comes from gluconeogenesis and gluconeogenesis accounts for about $50 \%$ of systemic glucose production. Therefore, in contrast to current opinion, the kidney contributes as much as the liver to overall gluconeogenesis. However, since the kidney simultaneously utilizes glucose in terms of net addition to plasma of glucose made gluconeogenetically, its contribution is half that of the liver.

Most metabolic experiments in humans have used tracer dilution techniques for the study of hepatic glucose production [29], assuming an insignificant contribution from the kidney. However, since the kidney contributes substantially to glucose turnover in the basal state and to an unknown extent during experimental perturbation or in pathological states, endogenous glucose production can no longer be assumed to equal hepatic glucose production.
Renal glucose production accounting for a quarter of all systemic glucose appearance should contribute significantly to the maintenance of normoglycaemia. This observation thus provides a possible explanation of why people with chronic renal failure are prone to develop hypoglycaemia [60-63]. Moreover, the stimulation of glucose release by epinephrine suggests an important role of the kidney in glucose counterregulation [64]. Finally, infusion of ethanol, known to inhibit whole body gluconeogenesis in humans [65], caused a mild hypoglycaemic response and a significant increase in net renal glucose release in dogs [66]. This suggests that ethanol selectively inhibits hepatic gluconeogenesis.

The association of uraemia and insulin resistance has long been recognized, although the exact pathogenesis is not fully understood [67]. The effects of uraemia on glucose production have not been unanimously established [68-70], since it is likely that offsetting mechanisms are operative. On the one hand, uraemia could induce hepatic insulin resistance whereby decreased insulin suppression of basal hepatic glucose production would result in an increase in glucose turnover. On the other hand, loss of renal glucose production would lead to a decrease in glucose appearance and insulin sensitivity.

The uptake of glucose by the kidney in the postabsorptive state is comparable to that reported for skeletal muscle [71, 72] and splanchnic tissues [73, 74]. If uptake of glucose by the kidney was regulated by insulin in humans as it is in dogs and rats $[12,28,75]$, the kidney could provide another explanation for the insulin resistance found in patients with chronic renal failure [76] since loss of a major target organ for insulin could result in insulin resistance. Requirements of exogenous insulin in IDDM patients who develop end-stage renal failure tend to decrease [77]. The most widely accepted explanation for this is loss of renal insulin excretion resulting in a prolonged biological half-life of the hormone [78]. However, decreased renal gluconeogenesis may be a contributing factor.

Regarding the pathogenesis of human diabetes, both IDDM and NIDDM are characterized by increased rates of glucose turnover [79]. In NIDDM, this overproduction of glucose has been established by several different experimental approaches to be predominantly the result of increased gluconeogenesis $[80,81]$. According to current belief, which is based on isotope dilution experiments and the assumption that renal glucose output is insignificant, this is thought to occur exclusively in the liver. The recent observations in IDDM and indirect data for NIDDM suggest a proportionate contribution of renal glucose production to the increased endogenous glucose production in both diseases. Thus, renal gluconeogenesis conceivably is important in the pathogenesis of fasting hyperglycaemia in NIDDM. 
Finally, the issue of insulin suppressing renal glucose production is important in the light of publications suggesting that systemic insulinization is as effective as portal insulinization in suppressing systemic glucose production [82-84]. If renal glucose production was sensitive to insulin, an explanation for these findings could be provided. Moreover, if renal glucose production was insulin sensitive, the insulin resistance of NIDDM could lead to overproduction of glucose by the kidney.

\section{Summary and conclusions}

In view of the evidence presented here, the traditional perception of the human kidney playing a minor role in glucose homeostasis should be abandoned. With its contribution to glucose production and glucose utilization, the kidney may be of considerable relevance in glucose counterregulation, postprandial glucose disposal, insulin resistance of uraemia and the pathogenesis of hyperglycaemia in diabetes.

\section{References}

1. Mayes PA (1993) Gluconeogenesis and control of the blood glucose. In: Murray RK, Granner DK, Mayes PA, Rodwell VW (eds) Harper's biochemistry. Appleton and Lange, East Norwalk, Connecticut, pp 190-200

2. Gerich JE (1993) Control of glycaemia. Baillieres Clin Endocrinol Metab 7: 551-586

3. Landau BR, Wahren J, Chaandramouli V, Schumann WC, Ekberg K, Kalhan SC (1996) Contributions of gluconeogenesis to glucose production in the fasted state. J Clin Invest 98: 378-385

4. Krebs HA (1963) Renal gluconeogenesis. Adv Enzyme Reg 1: 385-400

5. Björkman O, Felig P, Wahren J (1980) The contrasting responses of splanchnic and renal glucose output to gluconeogenic substrates and to hypoglucagonemia in 60-h-fasted humans. Diabetes 29: 610-616

6. Björkman O, Felig P (1982) Role of the kidney in the metabolism of fructose in 60-hour fasted humans. Diabetes 31: 516-520

7. Brundin T, Wahren J (1994) Renal oxygen consumption, thermogenesis, and amino acid utilization during iv infusion of amino acids in man. Am J Physiol 267: E648E655

8. Castellino P, DeFronzo RA (1990) Glucose metabolism and the kidney. Semin Nephrol 10: 458-463

9. Steinberg D (1991) Regulation of carbohydrate metabolism. In: Satterfield T (ed) Physiological basis of medical practice. Williams and Wilkins, Baltimore, pp 728-739

10. Felig P, Bergman M (1995) The endocrine pancreas: diabetes mellitus. In: Felig P, Baxter JD, Frohman LA (eds) Endocrinology and metabolism. McGraw-Hill, New York, pp 1107-1250

11. McGuinness OP, Fugiwara T, Murrell S et al. (1993) Impact of chronic stress hormone infusion on hepatic carbohydrate metabolism in the conscious dog. Am J Physiol 265: E314E322
12. Cersosimo E, Judd RL, Miles JM (1994) Insulin regulation of renal glucose metabolism in conscious dogs. J Clin Invest 93: 2584-2589

13. Stumvoll M, Welle S, Chintalapudi U, Perriello G, Gutierrez O, Gerich J (1995) Uptake and release of glucose by the human kidney: postabsorptive rates and responses to epinephrine. J Clin Invest 96: 2528-2533

14. Benoy MP, Elliot KAC (1937) The metabolism of lactic and pyruvic acids in normal and tumor tissue. V. Synthesis of carbohydrate. Biochem J 31: 1268-1275

15. Bergman H, Drury DR (1938) The relationship of kidney function to the glucose utilization of the extra abdominal tissues. Am J Physiol 124: 279-284

16. Reinecke RM (1943) The kidney as a source of glucose in the eviscerated rat. Am J Physiol 140: 276-280

17. Cohn C, Kolinsky M (1949) Effect of blood sugar levels and insulin lack on gluconeogenesis by the kidney of the dog. Am J Physiol 156: 345-348

18. Bollman JL, Grindlay JH (1952) Measurement of renal gluconeogenesis. Am J Physiol 170: 38-44

19. Drury DR, Wick AN, MacKay EM (1950) Formation of glucose by the kidney. Am J Physiol 163: 655-659

20. Saugman B (1951) Renal gluconeogenesis in eviscerated cats. Acta Physiol Scand 23: 187-189

21. Aber GM Morris LO, Housley E (1966) Gluconeogenesis by the human kidney. Nature 212: 1589-1590

22. Owen OE, Felig P, Morgan AP, Wahren J, Cahill GF Jr (1969) Liver and kidney metabolism during prolonged starvation. J Clin Invest 48: 574-583

23. Schoolwerth AC, Drewnowska K (1993) Renal metabolism. In: Schrier RW, Gottschalk CW (eds) Diseases of the kidney. Little Brown and Company, Boston, Toronto, London, pp 233-260

24. Nurjhan N, Kennedy F, Consoli A, Martin C, Miles J, Gerich J (1988) Quantification of the glycolytic origin of plasma glycerol: implications for the use of the rate of appearance of plasma glycerol as an index of lipolysis in vivo. Metabolism 37: 386-389

25. Jenssen T, Nurjhan N, Perriello G, Bucci A, Toft I, Gerich J (1994) Determination of $\left[{ }^{14} \mathrm{C}\right]$ glutamine specific activity in plasma. J Liq Chromat 17: 1337-1348

26. Schoolwerth AC, Smith BC, Culpepper RM (1988) Renal gluconeogenesis. Miner Electrolyte Metab 14: 347-361

27. Wirthensohn G, Guder WG (1986) Renal substrate metabolism. Physiol Rev 66: 469-497

28. Guder WG, Ross BD (1984) Enzyme distribution along the nephron. Kidney Int 26: 101-111

29. Stumvoll M, Overkamp D, Gerich JE (1995) A primer on tracer methods for the study of glucose metabolism in man. Diab Nutr Metab 8: 298-314

30. Consoli A, Nurjhan N, Reilly JJ Jr, Bier DM, Gerich JE (1990) Contribution of liver and skeletal muscle to alanine and lactate metabolism in man. Am J Physiol 259: E677E685

31. Stanley W, Gertz E, Wisneski J, Neese R, Morris D, Brooks G (1986) Lactate extraction during net lactate release in legs of humans during exercise. J Appl Physiol 60:1116-1120

32. Kida K, Nakago S, Kamiya F, Toyama Y, Takashi N, Nakagawa H (1978) Renal net glucose release in vivo and its contribution to blood glucose in rats. J Clin Invest 62: 721726

33. Biava C, Grossman A, West M (1966) Ultrastructural observations on renal glycogen in normal and pathologic human kidneys. Lab Invest 15: 330-356

34. Burch HB, Narins RG, Chu C et al. (1978) Distribution along the rat nephron of three enzymes of gluconeogenesis in acidosis and starvation. Am J Physiol 235: F246-F253 
35. Lupianez JA, Dileepan KN, Wagle SR (1979) Interrelationship of somatostatin, insulin and calcium in the control of gluconeogenesis in kidney cortex slices. Biochem Biophys Res Commun 90: 1153-1158

36. Rizza R, Mandarino L, Gerich J (1986) Dose-response characteristics for the effects of insulin on production and utilization of glucose in man. Am J Physiol 240: E630 E639

37. Mitrakou A, Plantanisiotis D, Vlachos L et al. (1996) Increased renal glucose production in insulin dependent diabetes (IDDM): contribution to systemic glucose appearance and effect of insulin repletion. Diabetes 45 [Suppl2]: 33A (Abstract)

38. Bowman RH (1970) Gluconeogenesis in the isolated perfused rat kidney. J Biol Chem 245: 1604-1612

39. Stumvoll M, Meyer C, Chintalapudi U et al. (1996) Human renal glucose and glutamine metabolism. Effects of glucagon. Diabetes 45 [Suppl2]: 34 A (Abstract)

40. Kurokawa K, Massry SG (1973) Evidence for stimulation of renal gluconeogenesis by catecholamines. J Clin Invest 52: 961-964

41. Sacca L, Vigorito C, Cicala M, Corso G, Sherwin RS (1983) Role of gluconeogenesis in epinephrine-stimulated hepatic glucose production in humans. Am J Physiol 245: E294E302

42. Mitrakou A, Ryan C, Veneman Tet al. (1991) Hierarchy of thresholds for activation of counterregulatory hormone secretion, symptoms, and cerebral dysfunction. Am J Physiol 260: E67-E74

43. Felig P, Wahren J, Hendler R, Brundin T (1974) Splanchnic glucose and amino acid metabolism in obesity. J Clin Invest 53: 582-590

44. Vinay P, Mapes JP, Krebs HA (1978) Fate of glutamine carbon in renal metabolism. Am J Physiol 234: F123-F129

45. Roobol A, Alleyne GAO (1973) Regulation of renal gluconeogenesis by calcium ions, hormones and adenosine 3' : 5'-cyclic monophosphate. Biochem J 134: 157-165

46. Roxe DM, Schreiner GE, Preuss HG (1973) Regulation of renal gluconeogenesis and ammoniagenesis by physiologic fuels. Am J Physiol 225 (4): 908-911

47. Krebs HA, Bennett DAH, DeGasquet P, Gascoyne T, Yoshida T (1963) Renal gluconeogenesis the effect of diet on the gluconeogenic capacity of rat kidney cortex slices. Biochem J 86: 22-28

48. Nurjhan N, Bucci A, Perriello G et al. (1995) Glutamine: a major gluconeogenic precursor and vehicle for interorgan carbon transport in man. J Clin Invest 95: 272-277

49. Lochs H, Roth E, Gasic S, Hubl W, Morse EL, Adibi SA (1990) Splanchnic, renal and muscle clearance of alanylglutamine in man and organ fluxes of alanine and glutamine when infused in free dual peptide forms. Metabolism 39: 833-836

50. Felig P, Wahren J, Räf L (1973) Evidence of interorgan amino acid transport by blood cells in humans. Proc Natl Acad Sci USA 70: 1775-1779

51. Gelfand RA, Glickman MG, Jacob R, Sherwin RS, De Fronzo RA (1986) Removal of infused amino acids by splanchnic and leg tissues in man. Am J Physiol 250: E407-E413

52. Meyer C, Stumvoll M, Chintalapudi U et al. (1996) Alanine and glutamine: selective markers for hepatic and renal gluconeogenesis in humans. Diabetes 45 [Suppl 2]: 255A (Abstract)

53. Teng C (1954) Studies on carbohydrate metabolism in rat kidney slices. II effects of alloxan diabetes and insulin administration on glucose uptake and formation. Arch Biochem Biophys 48: 415-423
54. Landau BR (1960) Gluconeogenesis and pyruvate metabolism in rat kidney, in vitro. Endocrinology 67: 744-751

55. Lemieux G, Aranda MR, Fournel P, Lemieux C (1984) Renal enzymes during experimental diabetes mellitus in the rat. Role of insulin, carbohydrate metabolism, and ketoacidosis. Can J Physiol Pharmacol 62: 70-75

56. Consoli A (1992) Role of liver in pathophysiology of NIDDM. Diabetes Care 15: 430-441

57. Lemieux G, Achkar M, Vinay P, Gougoux A (1982) Characteristics of ammoniagenesis and gluconeogenesis by the diabetic kidney. In vitro studies in the rat. Contrib $\mathrm{Ne}$ phrol 31: 23-28

58. Wahren J, Felig P (1975) Renal substrate exchange in human diabetes mellitus. Diabetes 24: 730-734

59. Stumvoll M, Perriello G, Nurjhan N et al. (1996) Glutamine and alanine metabolism in NIDDM. Diabetes 45: 863-868

60. Owen R (1989) Hypoglycemia associated with renal failure. Endocrinol Metab Clin North Am 18: 103-121

61. Garber AJ, Bier DM, Cryer PE, Pagliari AS (1974) Hypoglycemia in compensated renal insufficiency. Diabetes 23: 982-986

62. Fischer KF, Lees JA, Newman JH (1986) Hypoglycemia in hospitalized patients. N Engl J Med 315: 1245-1250

63. Arem R (1989) Hypoglycemia associated with renal failure. Endocrinol Metab Clin North Am 18: 103-121

64. Service F (1995) Hypoglycemic disorders. N Engl J Med 332: 1144-1152

65. Puhakainen I, Koivisto VA, Yki-Järvinen H (1991) No reduction in total hepatic glucose output by inhibition of gluconeogenesis with ethanol in NIDDM patients. Diabetes 40: 1319-1327

66. Jones VD, Spalding CT, Jenkins ML (1971) Ethanol induced hypoglycemia and renal gluconeogenesis. Res Comm Chem Pathol Pharmacol 2: 67-77

67. Adrogue HJ (1992) Glucose homeostasis and the kidney. Kidney Int 42: 1266-1282

68. Kalhan SC, Ricanati ES, Tserng K-Y, Savin SM (1983) Glucose turnover in chronic uremia: increased recycling with diminished oxidation of glucose. Metabolism 32: 11551162

69. DeFronzo RA, Alvestrand A, Smith D, Hendler R, Hendler E, Wahren J (1981) Insulin resistance in uremia. J Clin Invest 67: 563-568

70. Rubenfeld S, Garber AJ (1978) Abnormal carbohydrate metabolism in chronic renal failure. J Clin Invest 62: 20-28

71. Kelley D, Mitrakou A, Marsh H et al. (1988) Skeletal muscle glycolysis, oxidation, and storage of an oral glucose load. J Clin Invest 81: 1563-1571

72. Dinneen S, Gerich J, Rizza R (1992) Carbohydrate metabolism in non-insulin-dependent diabetes mellitus. N Engl J Med 327: 707-713

73. Mari A, Wahren J, DeFronzo RA, Ferrannini E (1994) Glucose absorption and production following oral glucose: comparison of compartmental and arteriovenous-difference methods. Metabolism 43: 1419-1425

74. DeFronzo R, Ferrannini E, Hendler R, Felig R, Wahren J (1983) Regulation of splanchnic and peripheral glucose uptake by insulin and hyperglycemia in man. Diabetes 32: 3545

75. Gregg CM, Cohen JJ, Black AJ, Espeland MA, Feldstein ML (1978) Effects of glucose and insulin on metabolism and function of perfused rat kidney. Am J Physiol 235: F52-F61

76. DeFronzo R, Abnestrand A, Smith D, Hendler R, Wahren $\mathrm{J}$ (1981) Insulin resistance in uremia. J Clin Invest 67: 563 568 
77. Rabkin R, Ryan MP, Duckworth WC (1984) The renal metabolism of insulin. Diabetologia 27: 351-357

78. Duckworth WC (1988) Insulin degradation: mechanisms, products, and significance. Endocr Rev 9: 319-345

79. DeFronzo RA, Simonson D, Ferrannini E (1983) Hepatic and peripheral insulin resistance: a common feature of type 2 (non-insulin-dependent) and type 1 (insulin-dependent) diabetes mellitus. Diabetologia 23: 313-318

80. Magnusson I, Rothman D, Katz L, Shulman R, Shulman G (1992) Increased rate of gluconeogenesis in type II diabetes. A ${ }^{13} \mathrm{C}$ nuclear magnetic resonance study. J Clin Invest 90: $1323-1327$

81. Consoli A, Nurjhan N, Capani F, Gerich J (1989) Predominant role of gluconeogenesis in increased hepatic glucose production in NIDDM. Diabetes 38: 550-561

82. Prager R, Wallace P, Olefsky J (1987) Direct and indirect effects of insulin to inhibit hepatic glucose output in obese subjects. Diabetes 36: 607-611

83. Giacca A, Fisher S, Gupta R, Shi Z, Lickley L, Vranic M (1992) Importance of peripheral mechanisms of insulin action for the regulation of hepatic glucose production in depancreatectomized dogs. J Clin Invest 90: 1769-1777
84. Ader M, Bergman R (1990) Peripheral effects of insulin dominate suppression of fasting hepatic glucose production. Am J Physiol 245: E1020-E1032

85. Owen OE, Robinson RR (1963) Amino acid extraction and ammonia metabolism by the human kidney during the prolonged administration of ammonium chloride. J Clin Invest 42: 263-276

86. Nieth H, Schollmeyer P (1966) Substrate-utilization of the human kidney. Nature 209: 1244-1245

87. Tizianello A, DeFerrari G, Garibotto G, Gurreiri G (1978) Effects of chronic renal insufficiency and metabolic acidosis on glutamine metabolism in man. Clin Sci 55: 391-397

88. Owen OE, Reichle FA, Mozzoli MA et al. (1981) Hepatic, gut, and renal substrate flux rates in patients with hepatic cirrhosis. J Clin Invest 68: 240-252

89. Ahlborg G, Weitzberg E, Sollevi A, Lundberg JM (1992) Splanchnic and renal vasoconstrictor and metabolic responses to neuropeptide $\mathrm{Y}$ in resting and exercising man. Acta Physiol Scand 145: 139-149 